\title{
Volume change behaviour of root-permeated soils under partially saturated conditions
}

\author{
Anil Yildiz ${ }^{1,2,3,4^{*}}$, Frank $_{\text {Graf }}{ }^{3}$, and Sarah M. Springman ${ }^{4}$ \\ ${ }^{1}$ National Green Infrastructure Facility, Newcastle upon Tyne, NE4 5TG, United Kingdom \\ ${ }^{2}$ School of Engineering, Newcastle University, NE1 7RU, United Kingdom \\ ${ }^{3}$ WSL Institute for Snow and Avalanche Research SLF, Davos Dorf, Switzerland \\ ${ }^{4}$ Institute for Geotechnical Engineering, ETH Zurich, Zurich, Switzerland
}

\begin{abstract}
Vegetation, particularly roots, serves different functions in relation to increased shear strength under saturated and partially saturated conditions. Quantification of mechanical contribution of roots due to their tensile strength, and relationships of various vegetation parameters and plant-induced suction, as well as shear strength, have been widely studied. Although shear strength is directly related to the volume change characteristics of soil, dilative or contractive behaviour of root-permeated soils has not been of significant interest so far. This study investigates how volume change during shearing is related to the hydrological and mechanical characteristics of vegetated soils relevant to slope stability and shear strength of root-permeated soils under partially saturated conditions. Direct shear tests, on specimens planted with a mixture of species from different plant functional groups, were performed with an Inclinable Large-scale Direct Shear Apparatus (ILDSA). Matric suctions were monitored throughout the test with tensiometers. Vertical and horizontal displacement graphs were plotted to investigate the volume change behaviour. Maximum dilatancy angle was found to be positively correlated with plant-induced suction and net normalised stress, both of which were linked to root biomass and the root:shoot ratio. It was found that maximum dilatancy is controlled by matric suction and net normal stress.
\end{abstract}

\section{Introduction}

Understanding and modelling the mechanical behaviour of any soil requires the evaluation of the volume change characteristics during shearing. Dilatancy, expansion in volume during shearing, has been thoroughly investigated, and is well established for soils under saturated conditions [1]. However, there are limited number of studies on the volume change behaviour of unsaturated soils.

Constant-water-content triaxial compression tests on a poorly graded sand were used to validate the stress dilatancy theories for unsaturated soils [2]. Models have been developed to quantify and explain the dilatant behaviour of unsaturated soils, such as an extension to the Modified Cam-Clay model [3] or a model defining the peak strength as a function of dilatancy [4].

Although a limited number of papers can be found in the literature on the dilatancy of unsaturated soils, common observations among them [5-8] are:

- more significant dilatant behaviour with increased suction under the same confining pressure,

- reduction in the dilatancy angle with increased confining pressure under constant suction,

- increased peak shear stress due to increased dilatancy.

Volume change behaviour of root-permeated soils during shearing has become more relevant in recent years. A modelling framework has been proposed incorporating definitions of void ratio for rooted soils and dilatancy [9], and measurements of dilatancy angle from large-scale direct shear tests on soils with a combination of plant species have been presented [10].

Both [9] and [10] are related to the shearing under saturated conditions, in which plants can contribute mechanically to the strength. However, plants not only provide mechanical contribution to the shear strength, they also change the hydrological regime of soil and cause partial saturation. Canopy interception reduces the amount of rainfall reaching the soil surface and delays the saturation process during a rainfall [11]. Water content of soil is reduced by water uptake due to roots and evapo-transpiration [12]. These reductions in water content lead to partial saturation, resulting in plantinduced suction. It was also shown that hydrological contribution of vegetation to the shear strength can be the same order of magnitude as the mechanical contribution [13]. Biotic parameters, e.g. root biomass, root:shoot area, leaf area index, were found to be positively correlated with matric suction [14, 15], suggesting that better plant growth can yield to enhanced plant-induced suction.

Direct quantification of the shear strength of rootpermeated soils under partially saturated conditions is rare $[16,17]$, and volume change behaviour of rooted soils is not considered in these studies. Large-scale direct shear tests with monitoring of suction have been performed on root-permeated soils under partially

\footnotetext{
Corresponding author: anil.yildiz@newcastle.ac.uk
} 
saturated conditions in this study to characterise the volume change behaviour of vegetated samples. The objective was to investigate the correlations between dilatancy angle and various biotic, as well as abiotic, parameters.

\section{Materials \& methods}

\subsection{Soil}

Numerous shallow landslides occurred all around Switzerland subsequent to a two-day period of heavy rainfall in August 2005. A study was conducted afterwards to document the landslides, consisting of information of slope geometry, soil type, land use etc. [18]. Fifty landslides were recorded around St. Antonien, Praettigau in the canton of Grisons. Soil used in this study was taken from landslide \#4023, which happened on a $25^{\circ}$ slope and had a depth of $1.3 \mathrm{~m}$.

Particles with a diameter greater than $20 \mathrm{~mm}$ were discarded, and characterisation tests were performed. The soil was classified as a clayey sand (SC), based on the Unified Soil Classification System (USCS), and its index properties are given in Table 1 .

Table 1. Index properties of soil used in this study

\begin{tabular}{|l|r|r|}
\hline Gravel-Sand-Fines & {$[\%]$} & $14.0-45.9-40.1$ \\
\hline Liquid limit & {$[\%]$} & 23.5 \\
\hline Plastic limit & {$[\%]$} & 13.7 \\
\hline Plasticity index & {$[-]$} & 9.8 \\
\hline Specific gravity & {$[-]$} & 2.69 \\
\hline
\end{tabular}

\subsection{Experimental programme}

Fig. 1a shows the three factors and two levels of each factor used in this study. Fig. 1b illustrates the treatments.

The variance in biodiversity on a vegetated slope in a (a)

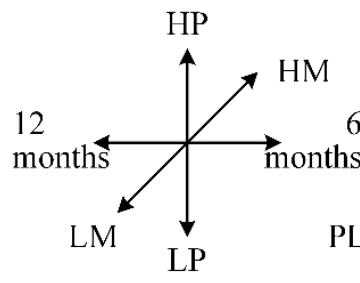

(b)

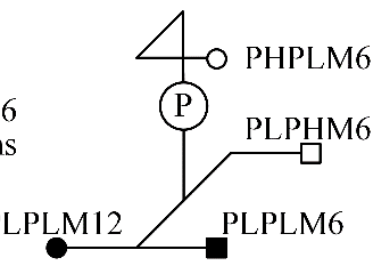

Fig. 1. (a) Factors used in this study, and (b) the experimental programme. P: Praettigau, LP: Low plant diversity, HP: High plant diversity, LM: Without mycorrhizal fungi and HM: With mycorrhizal fungi. 6 stands for the total plant growth time of 6 months, while 12 represents the growth time of 12 months.

subalpine grassland or a pasture was mimicked by plant diversity factor. "Low plant diversity" level (LP) consists of Poa pratensis (L.), Trifolium pratense (L.), and Alnus incana (L.) Moench., while "High plant diversity" level (HP) is composed of all the species in LP, as well as Anthyllis vulneraria (L.), Achillea millefolium (L.) and Salix appendiculata Vill. Species were chosen to be representative of different plant functional types and found commonly in grasslands and pastures in Switzerland [19] and used in soil bioengineering [20, 21].

Plant age effects were investigated with two plant growth durations, as 6 and 12 months. The treatment inoculated with mycorrhizal fungi (HM) were compared with the non-inoculated treatments (LM).

Samples were prepared in boxes with dimensions of $500 \times 500 \times 400 \mathrm{~mm}$, and air-dried soil was compacted in them up to a height of $300 \mathrm{~mm}$ (See [10] for details). Seedlings of the species according to the treatments were transferred to the shear boxes subsequent to saturating the soil in a water bath. Sample height in the shear box was not measured directly after saturation, but the mean and standard deviation of the sample height prior to shearing after the growth period was $271 \mathrm{~mm}$ and 8.7 $\mathrm{mm}$, respectively.

Direct shear tests were performed at the end of the corresponding growth period with the Inclinable Largescale Direct Shear Apparatus (ILDSA), shown in Fig. 2, at a constant rate of horizontal displacement of 1 $\mathrm{mm} / \mathrm{min}$ up to $190 \mathrm{~mm}$. Three levels of normal loads, 1.5 $\mathrm{kN}, 2.75 \mathrm{kN}$ and $4.0 \mathrm{kN}$, were applied, which exerted initial net normal stresses of $6 \mathrm{kPa}, 11 \mathrm{kPa}$ and $16 \mathrm{kPa}$. Matric suction was monitored with tensiometers around the shearing zone during shearing.

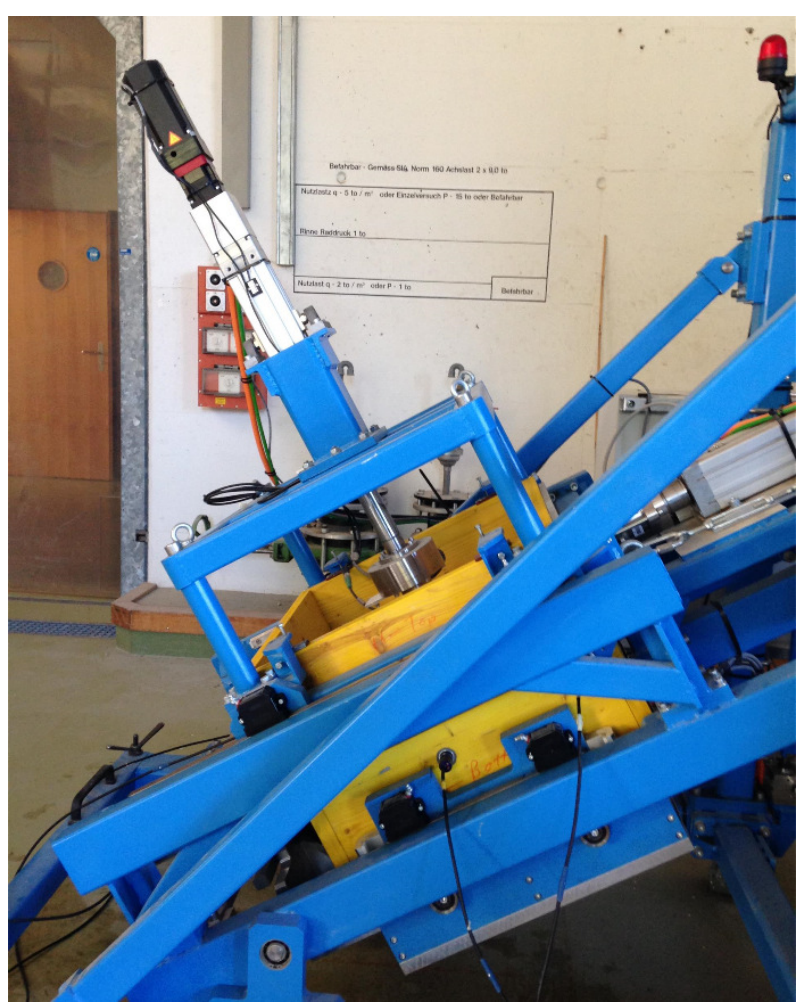

Fig. 2. Inclinable Large-scale Direct Shear Apparatus.

Above-ground biomass (AGB) was cut prior to testing, and the dry weight was obtained. Water content samples were taken from the surface and the shear zone as soon as the shearing finishes. Roots were dug out, washed, and then their dry weight was obtained. Further details of the treatments, sample preparation and testing can be found in [16]. 


\subsection{Data analysis}

The data analysis has been described in detail in [10] and [16]. As this study focusses on the volume change behaviour, vertical displacement data was first smoothed with a local polynomial regression, using the "Ipridge" function in $\mathrm{R}$ 3.5.2. The change in the normal displacement $(d y)$ was calculated at $2 \mathrm{~mm}$ steps of change in the shear displacement $(d x=2 \mathrm{~mm})$. Dilatancy angle $(\psi)$ was calculated as follows:

$$
\psi\left({ }^{\circ}\right)=\tan ^{-1}(d y / d x)
$$

Maximum dilatancy angle was defined as the highest value observed during shearing, and matric suction at the point where the peak shear stress occurs has been used for correlations.

\section{Results}

Parameters measured before and during the experiments are presented in [22] for all the experiments. A total of 21 partially saturated root-permeated soil samples were tested. Matric suctions were monitored during shearing, and the matric suction at peak shear stress was taken as the average value of the tensiometer readings. Matric suction ranged between $11 \mathrm{kPa}$ to $97 \mathrm{kPa}$. All samples showed dilatant behaviour during shearing, with maximum dilation angles ranging between $1.55^{\circ}$ and $18.1^{\circ}$. Only one sample started to dilate immediately following the initiation of shearing, while contraction was followed by expansion for all of the others.

The specimen with the highest matric suction at peak shear stress also had the highest maximum dilatancy angle, as well as highest normalised stress ratio. Lowest normalised stress ratio was obtained with the sample with the lowest maximum dilatancy angle, which had the lowest mean matric suction, i.e. $4 \mathrm{kPa}$, and second lowest matric suction at peak shear stress, i.e. $12 \mathrm{kPa}$ and the lowest is $11 \mathrm{kPa}$.

Fig. 3 presents the inter-relationships of maximum dilatancy angle, root biomass, mean water content, matric suction at peak shear stress and shear displacement at peak shear stress. Cells with grey background show that two parameters investigated are negatively correlated, whereas white background indicates a positive correlation.

First of all, it can be seen through corelations presented in Fig. 3 that maximum dilatancy angle was higher when the root biomass and matric suction was high. A decrease in mean water content also resulted in a pronounced dilatant behaviour. A higher dry weight of total root biomass yielded lower content, and in turn, higher matric suction. As can be expected for any unsaturated soil, matric suction was increasing with decreasing water content. Last parameter presented in Fig. 3 is the shear displacement at which peak shear stress occurs $\left(\mathrm{dx}_{\text {peak }}\right)$, which was found to be lower for specimens with high maximum dilatancy angles, matric suction, and root biomass.

Comparison of the treatments showed that the highest mean dilatancy angle, $9.6^{\circ}$, was exhibited by the specimen with the PLPLM12 treatment, whereas the lowest was for the PLPLM6, 7.0 ${ }^{\circ}$. Similar mean dilatancy angles, i.e. $7.8^{\circ}$ and $7.4^{\circ}$, were mobilised for the other two treatments, PLPHM6 and PHPLM6, respectively. PLPLM12 and PLPLM6 also had the highest and lowest mean matric suction [16].

\begin{tabular}{|c|c|c|c|c|}
\hline MAXD & RB & MWC & MSP & DXP \\
\hline \multirow[t]{3}{*}{ MAXD } & $0.36^{* *}$ & $0.70^{* * *}$ & $0.65^{* * *}$ & $0.69^{* * *}$ \\
\hline & RB & $0.54 * * *$ & $0.66^{* *}$ & $0.41 * *$ \\
\hline & & MWC & $0.65^{* * *}$ & $0.70 * * *$ \\
\hline \multicolumn{3}{|c|}{$\begin{array}{l}\square \text { Positively correlated } \\
\square \text { Negatively correlated }\end{array}$} & MSP & $0.64 * * *$ \\
\hline \multicolumn{4}{|c|}{ RB: Root biomass } & DXP \\
\hline \multicolumn{5}{|c|}{ MAXD: Maximum dilatancy angle } \\
\hline \multicolumn{5}{|c|}{ DXP: Shear disp. at peak shear stress } \\
\hline \multicolumn{5}{|c|}{$\begin{array}{l}\text { MSP: Matric suction at peak shear stress } \\
{ }^{*} \mathrm{p}<0.05,{ }^{* *} \mathrm{p}<0.01,{ }^{* * *} \mathrm{p}<0.001\end{array}$} \\
\hline
\end{tabular}

Fig. 3. Summary of correlations between maximum dilatancy angle, total root biomass, mean water content, matric suction at peak shear stress, and shear displacement at peak shear stress.

\section{Discussion}

Peak friction angle - critical state friction angle dilatancy angle relationship proposed by [1] relates the maximum dilatancy angle to a state parameter, relative density, and mean effective stress. As various researchers validated the stress-dilatancy relationships for unsaturated soils, it was also demonstrated that an increase in confining pressure results in less pronounced dilatant behaviour $[5,8,23]$. Method used in these works were to perform experiments at constant suction under various confining pressures.

The samples in this study were not tested under suction-controlled conditions, but suction was monitored during shearing. Furthermore, each sample had individual and unique plant growth performance although the plants were grown under nominally the same conditions. A comparison of maximum dilatancy angles at different levels of applied normal load would not help to isolate the variation due to confining pressure. Thus, boxplots of the maximum dilatancy angle with respect to three levels of effective stress tested are given in Fig. 4, showing the range of the dilatancy angles and median values at each stress level. Even though there were differences in matric suction values between samples, there is still a visible reduction in dilatant behaviour with increasing normal stress, as observed for fallow unsaturated soils.

Regardless of the differences in the levels of normal load applied during shearing, an increase in maximum 
dilatancy angle was observed with an increase in matric suction (See Fig. 5) $\left(\mathrm{R}^{2}=0.65, \mathrm{p}<0.001\right)$. This relationship was shown for unsaturated fallow soils, as well, derived from suction-controlled direct shear tests on completely decomposed granite $(\mathrm{CDG})$ soil $[6,7]$ and a coarse sand [8], as well as from suction-monitored direct shear tests on silts and silty sands [23].

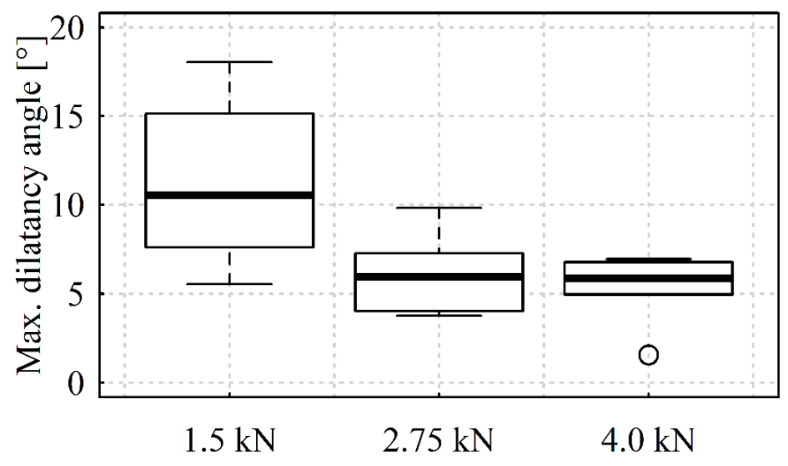

Fig. 4. Variation of maximum dilatancy angle at three levels of applied normal load.

As a proxy for brittleness, correlations of $\mathrm{dx}_{\text {peak }}$ were derived. A sample with a low $\mathrm{dx}_{\text {peak }}$ is considered to be highly brittle, i.e. a strain-softening behaviour, whereas if a sample reached to peak shear stress at a later stage of shearing, i.e. higher $\mathrm{dx}_{\text {peak }}$, it is considered to be ductile. Negative correlation between the matric suction and $\mathrm{dx}_{\text {peak }}$ suggests that samples with high suction values shows brittle behaviour.

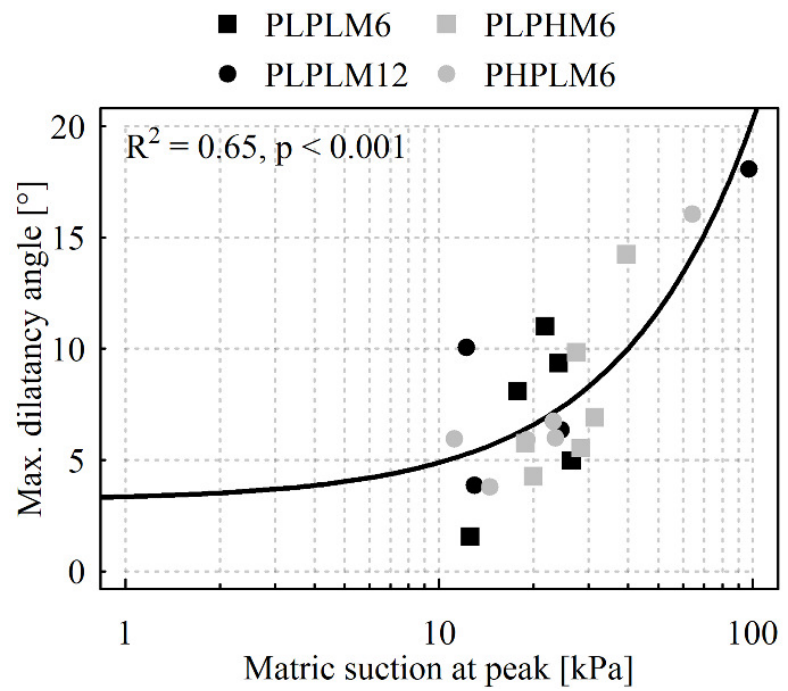

Fig. 5. Maximum dilatancy angle - matric suction at peak for all samples.

Fig. 6 shows three experiments conducted at the lowest applied normal load with higher matric suction values, $39.6 \mathrm{kPa}, 64.4 \mathrm{kPa}$ and $97.2 \mathrm{kPa}$. Shear force displacement graphs presented in Fig. 6 are typical of strain-softening behaviour. Mobilisation of peak shear stress at smaller shear displacements was observed for silty clays tested in a triaxial apparatus, when the matric suction was high. This was attributed to the greater stiffness of the material under higher matric suction values [25]. Results of suction-monitored direct shear box on silts suggest that significant differences between the peak and ultimate shear stress occurs only at low normal stresses, i.e. $35 \mathrm{kPa}$, due to strong bonding around soil particles [24].

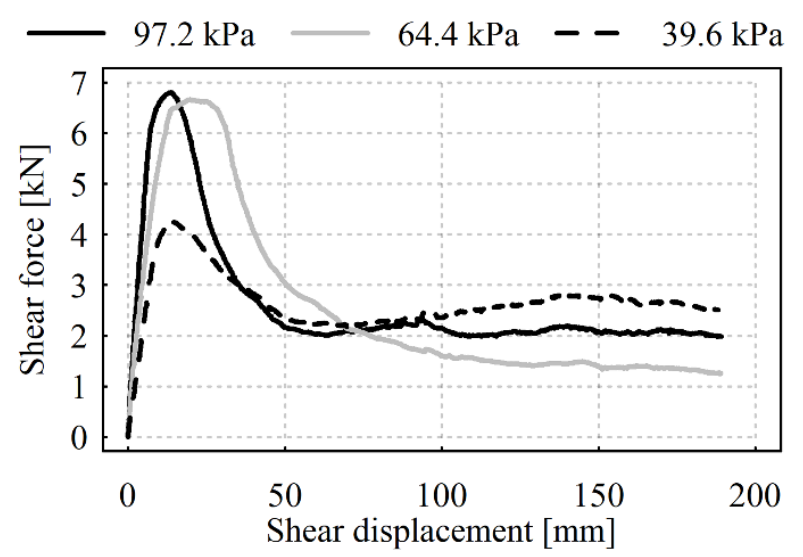

Fig. 6. Shear force - displacement graphs of samples with the highest matric suctions in this study.

Fig. 7 illustrates the dilatancy angle - shear displacement graphs of the same samples presented in Fig. 6. The highest dilatancy angle, $18.1^{\circ}$, was observed for the sample with the highest matric suction. The samples with medium and lower suctions exhibited maximum dilatancy angles of $16.0^{\circ}$ and $14.2^{\circ}$, respectively. Similar increases in dilatancy at constant confining pressure was also shown previously [5].

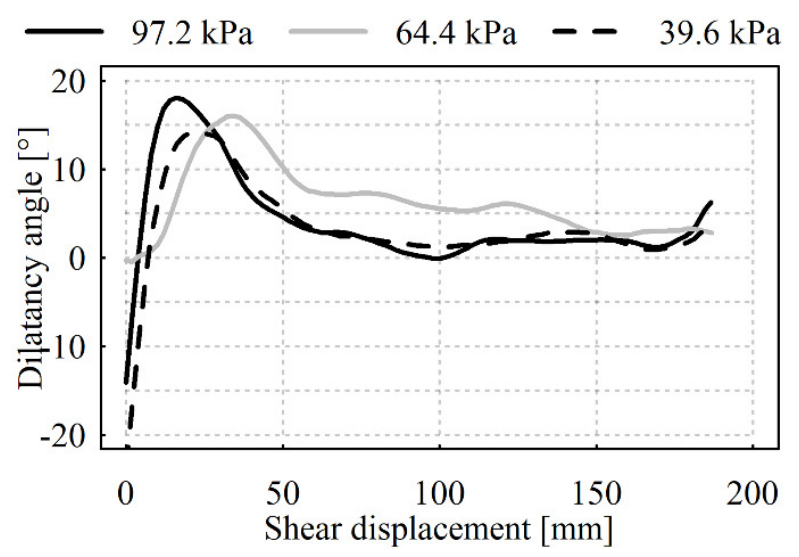

Fig. 7. Dilatancy angle - shear displacement graphs of tests with highest matric suctions in this study.

Correlations presented in Fig. 3 establish a relationship between root biomass and maximum dilatancy angle, but this does not present enough evidence to claim that presence of roots can alter the dilatant behaviour. An examination of the correlations between root biomass, water content and matric suction indicate that a higher root biomass resulted in lower water content, which implies higher matric suction. Maximum dilatancy angles measured in this study is due to variation in both the net normal stress and the matric suction. This variation prevents quantifying the direct effects of roots on the dilatancy, but explains the volume change characteristics resulting from partial saturation. 
Mahannopkul and Jotisankasa (2019) performed suctionmonitored direct shear tests and concluded that an increase in root content caused a decrease in dilatancy angle at the same level of suction, but increasing suction resulted in higher values of maximum dilatancy angle [26]. A similar outcome cannot be deduced from these experiments, as they were performed under varying matric suction. However, enhancement of suction due to vegetation is evident, and plant-induced suction was linked to normalised shear stress and penetration resistance $[14,16]$.

\section{Conclusions}

This research presents dilatancy angle and suction measurements from large-scale direct shear tests on rootpermeated soils under partially saturated conditions. Results indicate that the dilatancy of the unsaturated rooted soils is controlled by net normal stress and matric suction. A higher root content increased the plantinduced suction, which in turn, enhanced the dilatancy. Future work should focus on isolating the contribution of roots and matric suction on the dilatant behaviour of the unsaturated soils.

\section{Acknowledgments}

This study was funded by the Swiss National Science Foundation within the framework of the National Research Programme 68 "Sustainable Use of Soil as a Resource" (NRP 68, Project no. 143122).

\section{References}

1. M.D. Bolton, Géotechnique, 36, 65-78 (1986)

2. E.J. Fern, D.J. Robert, K. Soga, J. Geotech. Geoenviron., Eng. 142, 04016055 (2016)

3. E.E. Alonso, A. Gens, A. Josa, Géotechnique 40, 405-430 (1990)

4. C.F. Chiu, C.W.W. Ng, Géotechnique 53, 809-829 (2003)

5. E. Cattoni, M. Cecconi, V. Pane, Bull. Eng. Geol. Environ. 66, 403-414 (2007)

6. M.A. Hossain, J.H. Yin Can. Geotech. J. 47, 11121126 (2010)

7. C.W.W. Ng, R.Z.B. Zhou, Proc. of $16^{\text {th }}$ Int. Conf. on Soil Mechanics, 2, 559-562 (2005)

8. R. Schnellmann, H. Rahardjo, H.R. Schneider, Eng. Geol. 162, 88-96 (2013)

9. D. Muir Wood, A. Diambra, E. Ibraim Soils Found. 56, 765-778 (2016)

10. A. Yildiz, F. Graf, C. Rickli, S.M. Springman, Catena 166, 98-113 (2018)

11. C.W.W. Ng, J.J. Ni, A.K. Leung, C. Zhou, Z.J. Wang, Géotechnique, 66 711-724 (2016)

12. G.E. Blight, Géotechnique 53, 55-64 (2003)

13. G. Veylon, M. Ghestem, A. Stokes, A. Bernard, Can. Geotech J. 52, 1839-1849 (2015)

14. D. Boldrin, A.K. Leung, A.G. Bengough Plant Soil 416, 437-451 (2017)
15. J.J. Ni, A.K. Leung, C.W.W. Ng, P.S. So Can. Geotech. J. 54, 561-573 (2017)

16. A. Yildiz, F. Graf, C. Rickli, S.M. Springman, Proc. of the Inst. Of Civil Eng. - Geotechnical Eng., 180209 (2019)

17. A. Gonzalez-Ollauri, S.B. Mickovski, Geoderma 285, 141-150 (2017)

18. C. Rickli, F. Graf For. Snow Landsc. Res. 82, 33-44 (2009)

19. M. Pohl, D. Alig, C. Körner, C. Rixen Plant Soil 324, 91-102 (2009)

20. R. Stangl Proc. $1^{\text {st }}$ Int. Conf. on Eco-Engineering 287-296 (2007)

21. F. Rey, M. Burylo, Geomorphology 204, 564-572 (2014)

22. A. Yildiz (2017) doi: 10.17632/y7w4jb37gc.1

23. Y.J. Cui, P. Delage, Géotechnique 46, 291-311 (1996)

24. A. Jotisankasa, W. Mairaing, J. Geotech. Geoenviron. Eng. 136, 533-537 (2010)

25. H. Rahardjo, H. Leong, R.B. Rezaur, Proc. of the Int. Conf. on Problematic Soils (2003)

26. K. Mahannopkul, A. Jotisankasa, Soils Found. 59, 500-516 (2019) 